\title{
Experimental Study of the Performance of Porous Materials to Enhance the Soil Cooling in Hot and Humid Regions
}

\author{
Keng Wai Chan and Kuok Soon Chan
}

\begin{abstract}
Soil has been proven as a promising cooling source in arid region, yet it has underperformed in hot-humid tropical countries. This paper aims to investigate the cooling performance (soil temperature) in hot and humid regions under the enhancement of different porous materials such as gravel woodchips and rice husk. Two experiments were conducted to evaluate the materials. In the first experiment, the performance of the surface covered by these materials was compared with other surface conditions such as the empty surface and the surface covered by a building model. The soil temperature at the depth of $0.25 \mathrm{~m}$ and $1.00 \mathrm{~m}$ below the surface covered by wood chips is the lowest, $0.8^{\circ} \mathrm{C}$ and $0.4^{\circ} \mathrm{C}$ lower compared to the soil temperature of the empty soil surface. In the second experiment, the porous materials were examined under the desired radiation intensity $\left(1000 \mathrm{Wm}^{-2}\right)$ from a halogen lamp. The soil surface covered $2 \mathrm{~cm}$-thick and $5 \mathrm{~cm}$-thick wood chips is $3^{\circ} \mathrm{C}$ and $4^{\circ} \mathrm{C}$ lower than the soil surface covered by gravel. The soil under the 2-cm-thick rice husk has the lowest temperature. Its soil surface is $1^{\circ} \mathrm{C}$ lower than the soil surface covered by 5 cm of wood chips.
\end{abstract}

Index Terms-Hot and humid regions, passive cooling, porous materials, soil cooling, tropical countries.

\section{INTRODUCTION}

Climate change is starting to have a real effect - nine out of the ten warmest years on the record began in 1880 are in $21^{\text {st }}$ century [1]. The energy used by air conditioning systems already constitute the major domestic use in the US and China, and is rapidly increasing in Malaysia. In a report presented by Chan [2], energy consumed by the refrigerator and the air conditioner in a residential terrace house is 4.1 MWh, which is $59 \%$ of the total annual energy consumption. Meanwhile, $64 \%$ of the total annual energy consumption in a single storey office, or $148.4 \mathrm{MWh}$ is used for air conditioning [2]. The air conditioning has become an important element in life as the living standards rise. Its demand across the globe is expected to increase exponentially in the next hundred years [3,4]. Therefore, an alternative air conditioning system that operates without compressor and refrigerant not only can reduce the energy load of the grid, but also reduce the carbon footprint of buildings.

The conventional cooling effect is produced through the compression, condensation, expansion and evaporation of a

Manuscript received November 29, 2012; revised December 15, 2012.

The authors are with School of Mechanical Engineering, Universiti Sains Malaysia (USM), 14300, Nibong Tebal, Penang, Malaysia (e-mail: kengwai.chan@eng.usm.my; alvison0052@yahoo.com). refrigerant. Among these processes, the compression of the refrigerant consumes the most energy. An alternative cooling source that is being considered in this paper is soil [5-8]. From a report presented by Climatetemp [9], the maximum and minimum ambient temperatures in Kuala Lumpur are $33^{\circ} \mathrm{C}$ and $22^{\circ} \mathrm{C}$, respectively. Givoni $[10,11]$ found that the maximum temperature of the dry bare soil at $60 \mathrm{~cm}$ under the ground is $29^{\circ} \mathrm{C}$ while the maximum ambient temperature above the ground is $34^{\circ} \mathrm{C}$. However, after the soil was irrigated in the early morning and covered by a $10 \mathrm{~cm}$ thick gravel layer, the temperature of the wet soil at the same level under the ground is $22^{\circ} \mathrm{C}$. Furthermore, the temperature fluctuations throughout a day for the dry soil and wet soil are only $2^{\circ} \mathrm{C}$ and $1^{\circ} \mathrm{C}$ respectively. Hamada et al. [6] performed an experiment using a polyethylene (PE) tube with the inner diameter of $0.052 \mathrm{~m}$ and length of $83.2 \mathrm{~m}$. The tube was buried at the depth between $3 \mathrm{~m}$ and $12 \mathrm{~m}$. When the volumetric flow rate of the brine is $0.12 \mathrm{~ms}^{-1}$, the brine's return temperature from ground is $18.4^{\circ} \mathrm{C}$, while the outdoor temperature is $26.2^{\circ} \mathrm{C}$, and the rejected heat is $0.638 \mathrm{kWh}$. Sanusi et al. [7] buried three PE tube with the inner diameter of $0.076 \mathrm{~m}$ and length of $30 \mathrm{~m}$ separately at the depth of $0.5 \mathrm{~m}$, $1.0 \mathrm{~m}$ and $1.5 \mathrm{~m}$. When the air flow in the tube is $5.6 \mathrm{~ms}^{-1}$, they found that the average temperature drop of the return air from polyethylene pipes $1 \mathrm{~m}$ under the ground is $6.7^{\circ} \mathrm{C}$. Bansal et al. [13] presented a simulation on the earth air tunnel evaporative cooling system using computational fluid dynamics (CFD) platform. The simulation result was verified by the experimental work set up in Ajmer. Cylindrical pipe made of Polyvinyl chloride (PVC) with the inner diameter of $0.15 \mathrm{~m}$ and length of $23.42 \mathrm{~m}$ was buried at the depth of $2.7 \mathrm{~m}$. When the air velocity is set at $5.0 \mathrm{~ms}^{-1}$ in summer, the temperature difference of the air at the inlet and outlet is $11.2^{\circ} \mathrm{C}$

However, little work has been done to justify the cooled soil being an ideal cooling source for building in hot-humid tropical countries like Malaysia. The previous researches are mainly conducted in arid regions [10-13]. Hot and dry climates accelerate the evaporation rate as well as the cooling process. However, tropical countries such as Malaysia, is warm and humid throughout the year. The humidity of the ambient air can affect the evaporation process in soil, thus reducing the cooling effect. Wanphen and Nagano [14] investigated several porous and non-porous materials, namely pebbles, silica sand, volcanic ash and silicecous shale, on their performance to moderate the roof surface temperature. Samples of $0.250 \mathrm{~m} \times 0.250 \mathrm{~m} \times 0.075 \mathrm{~m}$ were 
tested in a wind tunnel. After the 48 hours test at constant air temperature of $25^{\circ} \mathrm{C}$, relative humidity of $60 \%$ and wind velocity of $2.5 \mathrm{~ms}^{-1}$, the silica sand has the lowest surface temperature while the pebbles have the highest surface temperature. However, when the Metal Halide lamp above the sample was switched on, the surface temperature of the silica sand was the highest, reaching $50^{\circ} \mathrm{C}$. Meanwhile the pebbles and silicecous shale with diameter more than $10 \mathrm{~mm}$ have the lowest surface temperature $\left(38^{\circ} \mathrm{C}\right)$ when the lamp was switched on. In order words, silica sand might be a medium with good absorption and evaporation rate, but the pebbles and silicecous shale are the better mediums in blocking the solar radiation. The tests were conducted under controlled conditions that might not reflect the performance of the materials in hot and humid regions.

In this paper, several surface conditions were adopted to investigate the basic cooling performance of the coverings. The diurnal soil temperature beneath gravel, wood chips and a building model were measured and compared. Subsequently, the porous materials were further examined under the desired solar radiation intensity. Temperature and weight loss were measured and applied for the evaluation.

\section{EXPERIMENTAL SETUP}

\section{A. Soil under Different Coverings - Open Outdoor Condition}

The experiment was conducted at School of Mechanical Engineering Universiti Sains Malaysia, Penang, Malaysia. A soil surface with dimension of $3.0 \mathrm{~m} \times 2.0 \mathrm{~m}$ was divided into four sections, three of the section surfaces were covered by gravel, wood chips and a $0.5 \mathrm{~m} \times 0.5 \mathrm{~m} \times 0.4 \mathrm{~m}$ building model respectively (Fig. 1). One of the section surface, was used as the controlled area, which was left empty on its surface. The thickness of the gravel and wood chips layers are $1 \mathrm{~cm}$.

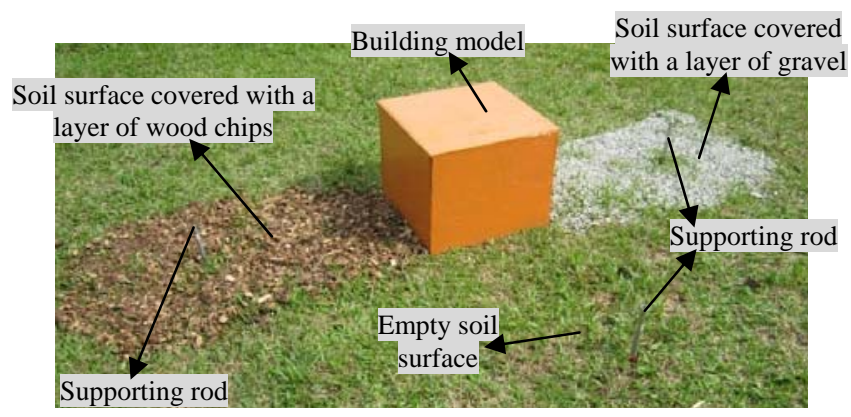

Fig. 1. Experimental setup

Four supporting rods with the length of $1.2 \mathrm{~m}$ were pierced into the ground to the depth of $1.0 \mathrm{~m}$ (Fig. 2). Calibrated Type $\mathrm{K}$ thermocouples were attached to the supporting rod to measure the soil temperature at the depth of $0.0 \mathrm{~m}$ (surface), $0.25 \mathrm{~m}, 0.50 \mathrm{~m}$ and $1.0 \mathrm{~m}$ below the surface (Fig. 3). The soil temperature was recorded for a continuous 72 hours (3 days) using PicoTech TC-08 data logger.

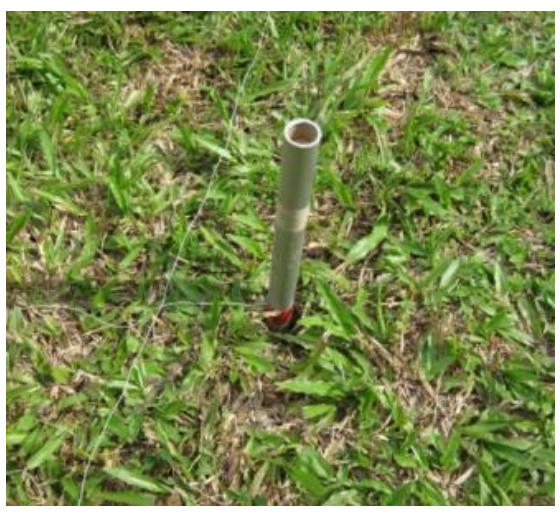

(a)

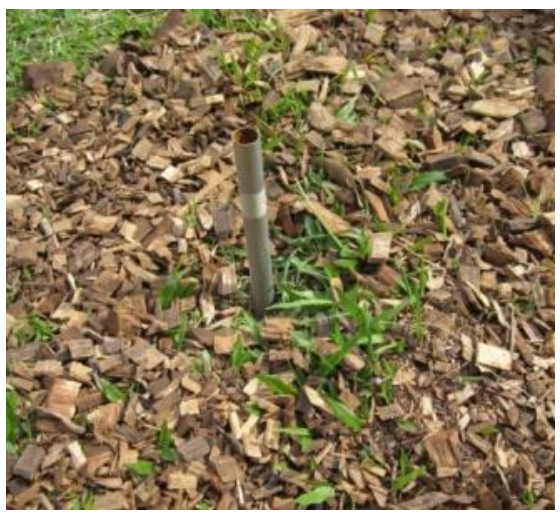

(b)

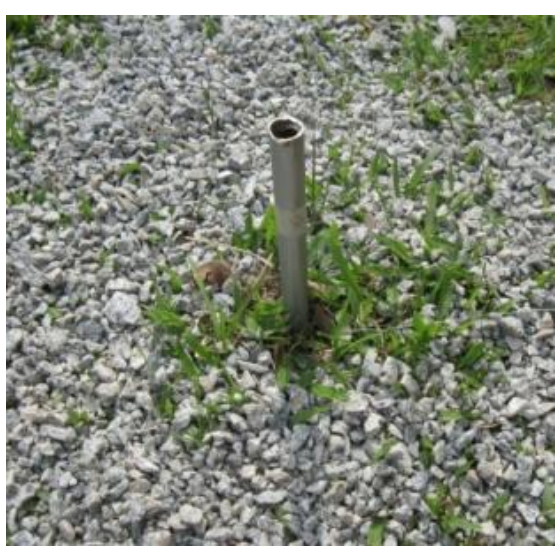

(c)

Fig. 2. Supporting rod pierced in (a) empty soil surface with soil surface and soil covered by (b) wood chips and (c) gravel

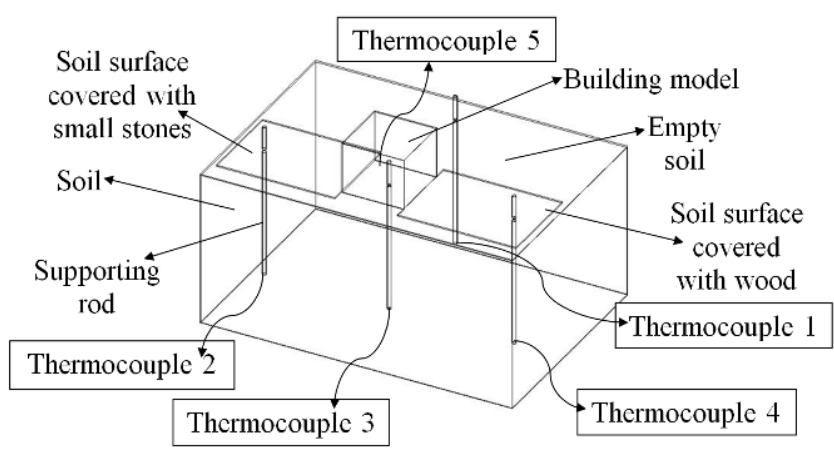

Fig. 3. Schematic diagram of the experimental setup

\section{B. Soil under Different Coverings - Indoor Controlled Condition}

This experiment was conducted to investigate the soil temperature under the enhancement of different porous 
mediums. Five different conditions were set up, containers with dimension of $0.14 \mathrm{~m} \times 0.17 \mathrm{~m} \times 0.23 \mathrm{~m}$ were first filled with soil to a depth of $0.18 \mathrm{~m}$, then four of the containers were added a layer of gravel ( $2 \mathrm{~cm}$ thick), wood chips $(2 \mathrm{~cm}$ and $4 \mathrm{~cm}$ thick) and rice husk (2 $\mathrm{cm}$ thick), respectively (Figure 4). Iso-Tech ISM410 solar power meter was used to determine the height of each container so that their surface receives the desired radiation intensity $\left(1000 \mathrm{Wm}^{-2}\right)$ from the halogen lamp. In order to block the heat and light from neighbouring compartments, each container was segregated by a separator. Three calibrated Type K thermocouples were inserted into each container, namely surface, middle (except for rice husk) and bottom. The soil temperature was recorded for three cycles of 90 minutes using PicoTech TC-08 data logger.

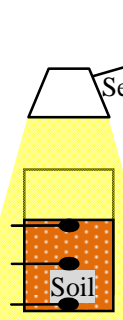

(a)

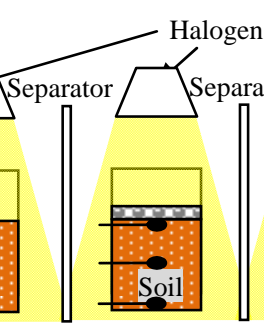

(b)

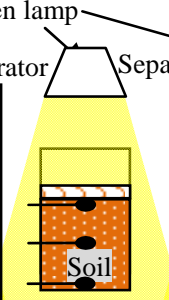

(c)

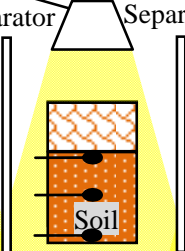

(d)

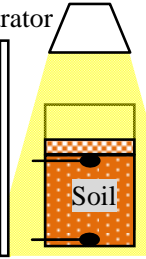

(e)
Fig. 4. Schematic diagram of the experimental setup: (a) empty soil surface, (b) soil covered by $2 \mathrm{~cm}$ gravel layer, (c) soil covered by $2 \mathrm{~cm}$ wood chips layer, (d) soil covered by $5 \mathrm{~cm}$ wood chips, and (e) soil covered by $2 \mathrm{~cm}$ rice husk. Thermocouples are placed at surface, middle (except for rice husk) and bottom of the container.

\section{RESULT AND DISCUSSION}

\section{A. Soil under Different Coverings - Open Outdoor Condition}

Figure 5 shows that the outdoor temperature increases rapidly after $8.00 \mathrm{am}$, and starts decreasing after $6.00 \mathrm{pm}$ since there is no direct sunlight on the building model (blocked by other buildings). The outdoor temperature ranged between $24^{\circ} \mathrm{C}$ and $38^{\circ} \mathrm{C}$.

The temperatures at soil surface have big variation (Figure 5(a)) compared to other soil temperature below the surface. The temperatures at soil surface have similar temperature profile pattern to the outdoor temperature profile. As the depth increases, the variation of the soil temperature throughout a day decreases. The variation at the soil surface is $7^{\circ} \mathrm{C}$, it drops to $0.9^{\circ} \mathrm{C}, 0.7^{\circ} \mathrm{C}$ and $0.1^{\circ} \mathrm{C}$ at $0.25 \mathrm{~m}, 0.50 \mathrm{~m}$ and $1.00 \mathrm{~m}$ below the surface respectively (Figure 5(b)-(d)). The soil surface temperatures increase rapidly after $9.00 \mathrm{am}$ and reach their maximum at noontime. After $3.30 \mathrm{pm}$, the temperatures of soil surface start to decrease and reach their minimum at nighttime. This shows that the temperatures of soil surface are influenced by the convection heat transfer from the ambient and the radiation heat transfer from the sunlight.

\section{1) Gravel}

The soil surface covered by gravel has the highest temperature among the samples regardless the depth of soil (Fig. 5). This is because gravel has higher thermal conductivity than wood chips and soil. Gravel absorbs the energy from sunlight and transfers it to the soil surface through conduction and radiation. This causes the soil surface to dry. As the soil surface dries, the thermal conductivity of the soil reduces. The dried soil becomes an insulative layer and moderates the heat transfer from underground to ambient.

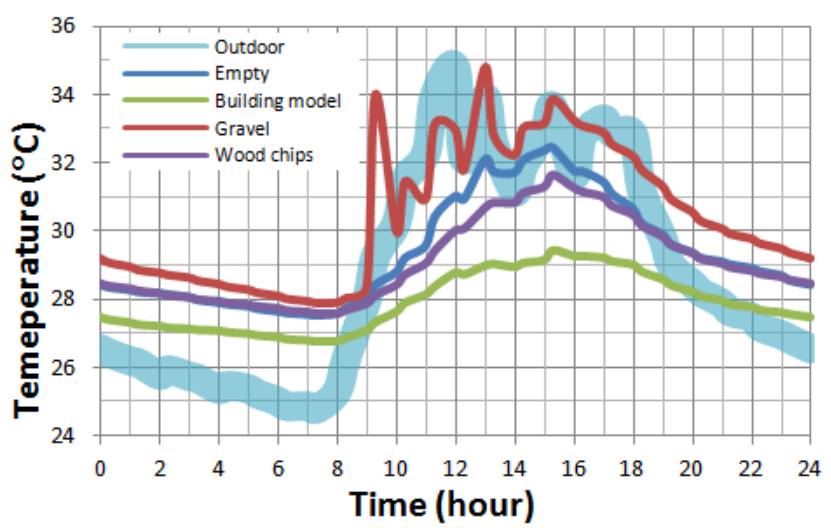

(a)

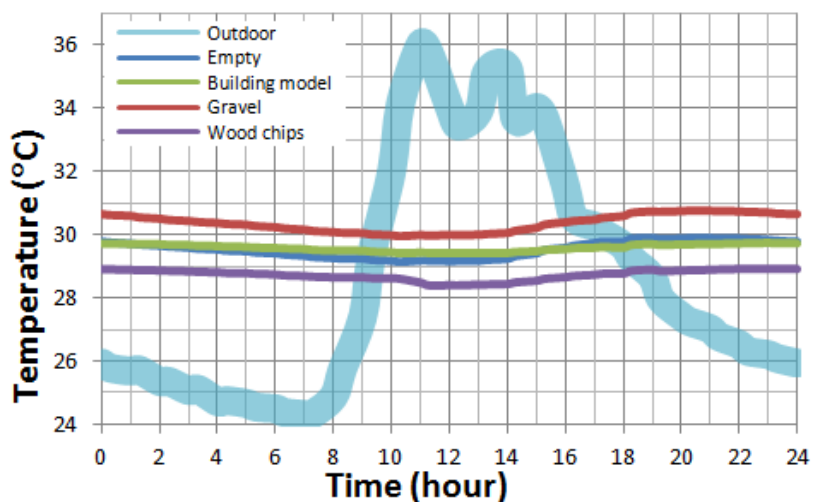

(b)

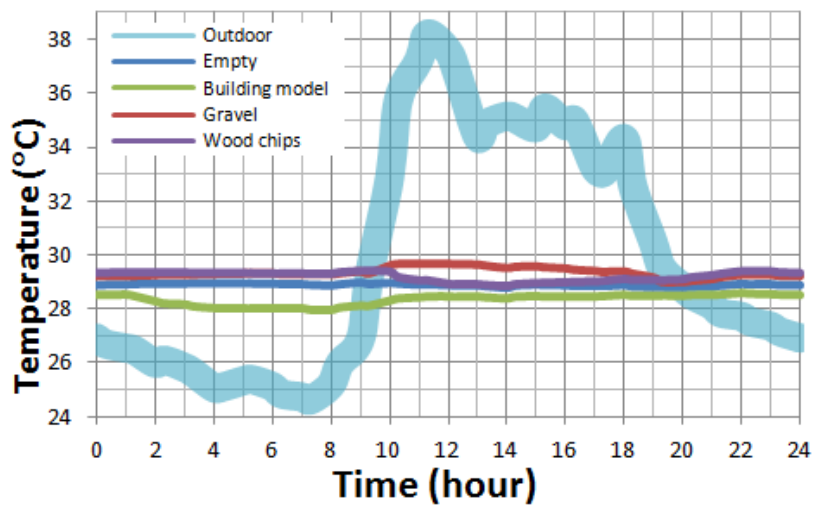

(c)

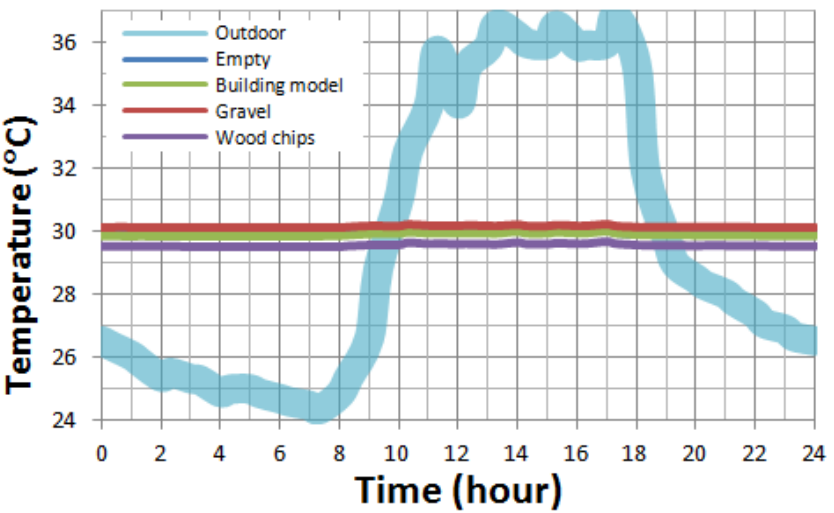

(d)

Fig. 5. Soil temperature (a) at the surface, (b) at the depth of $0.25 \mathrm{~m}$ below soil surface, (c) at the depth of $0.50 \mathrm{~m}$ below soil surface, and (d) at the depth of $1.00 \mathrm{~m}$ below soil surface 


\section{2) Building model}

The soil surface covered by a building model has the lowest temperature compared to the empty soil surface and the soil surface covered by gravel and wood chips (Figure 5(a)). The soil surface inside the building model is not exposed to the direct sunlight. The heat gain of the building model causes the temperatures of the indoor air and the soil surface to increase via the convective and radioactive heat transfer.

Fig. 5(b) and (d) show that the soil temperatures below the uncovered (empty) surface and the surface covered by a building model are close, yet the latter is slightly lower than the former. Unlike the soil under the building model, the uncovered soil is exposed to sunlight directly. Fig. 5(c) shows that the soil at the depth of $0.50 \mathrm{~m}$ below the surface covered by a building model has the lowest soil temperature. This situation occurs due to the rainy days. The rain water and low ambient temperature cool the building model and induce the convective and radioactive heat transfer from the soil to the indoor air and the building model. In addition, wet soil has a higher thermal conductivity, hence, all the soil temperatures at the depth of $0.50 \mathrm{~m}$ are below $30^{\circ} \mathrm{C}$.

\section{3) Wood chips}

Referring to Figure 5(a), the soil surface temperatures of the empty soil surface and the surface covered by wood chips are approximate. However, during daytime (8.00 am to 6.00 $\mathrm{pm})$, the temperature of empty soil surface is slightly higher than soil surface covered by wood chips. During this period, the temperature of soil surface covered by wood chips is $0.8^{\circ} \mathrm{C}$ lower compared to temperature of empty soil surface.

The soil temperature at the depth of $0.25 \mathrm{~m}$ and $1.00 \mathrm{~m}$ below the surface covered by wood chips is the lowest amongst the samples (Fig. 5(b), (d)). Even at noontime, the soil temperature at the depth of $0.25 \mathrm{~m}$ and $1.00 \mathrm{~m}$ below the surface covered by wood chips is $0.8^{\circ} \mathrm{C}$ and $0.4^{\circ} \mathrm{C}$ lower compared to the soil temperature at the same depths below the empty soil surface. Wood chips have low thermal conductivity than soil. They have ability to absorb water during rainy days. Wood chips will act as a heat barrier for soil surface. During noontime, the solar radiation falls on the wood chips may cause the water absorbed by them to evaporate even on cloudy and rainy days (Figure 5(c)). Through the evaporation process, the heat within soil is extracted.

\section{B. Soil under Different Coverings - Indoor Controlled Condition}

In the first experiment, the wood chips layer has proven their ability to reduce the soil temperature though the layer was only $1 \mathrm{~cm}$ thick. The second experiment was carried out to further investigate the performance of wood chips and rice husk to reduce the temperature of the soil.

Fig. 6(a) shows that the soil surface temperature for various surfaces, namely the empty surface, surface covered by gravel (thickness of $2 \mathrm{~cm}$ ), surface covered by wood chips (thickness of $2 \mathrm{~cm}$ and $5 \mathrm{~cm}$ ) and surface covered by rice husk (thickness of $2 \mathrm{~cm}$ ). The figure shows that the temperature of the empty surface increase rapidly when the halogen lamp is switched on. This is because the soil surface is exposed to the light directly. The soil surface covered by gravel has high temperature compared to the soil surface covered by wood chips and rice husk. And as the experiment continued beyond 90 minutes, the temperature of the soil surface covered by gravel has overtaken the empty soil surface. This is because the gravel has higher thermal conductivity than wood chips and rice husk. The gravel absorbs the energy from the light and transfers it to the soil surface through conduction and radiation. Meanwhile, the soil surface covered wood chips layer of $2 \mathrm{~cm}$ and $5 \mathrm{~cm}$ is $3^{\circ} \mathrm{C}$ and $4^{\circ} \mathrm{C}$ lower than the soil surface covered by gravel. This is because the wood chips have ability to absorb water like sponge. Furthermore, wood chips have low thermal conductivity than soil, hence it will act as a heat barrier for soil surface. Notwithstanding, when light (heat) falls on the wood chips, evaporation happens and removes the heat within the soil. It is worth mentioning that the soil under the 2-cm-thick rice husk has the lowest temperature. Its soil surface is $1^{\circ} \mathrm{C}$ lower than the soil surface covered by $5 \mathrm{~cm}$ of wood chips. The rice husk that capable to absorb water has a higher surface area than the wood chips. This might increase its evaporation rate and thus its cooling performance.

All the temperature profiles at the middle of the container show the similar pattern - drop to a minimum point and then increase (Fig. 6(b)). This might be caused by the evaporation process above the measuring level. When the evaporation process happens, the heat within the soil is extracted and released into the atmosphere. However, as the experiment continues, the soil temperature increases when the soil dries up.

The drying up process might not reach the bottom of the container within the 90 minutes experimental period. As the wet soil has a better thermal conductivity than dried soil, the wet soil at the bottom has a general trend of increase in temperature (Fig. 6(c)). Notwithstanding, the soil temperature of the soil surface covered by $2 \mathrm{~cm}$-thick and $5 \mathrm{~cm}$-thick wood chips is $0.5^{\circ} \mathrm{C}$ and $0.8^{\circ} \mathrm{C}$ lower than the soil with empty surface and soil covered by gravel, respectively. In addition, the soil temperature of the soil surface covered by $2 \mathrm{~cm}$-thick rice husk is $0.5^{\circ} \mathrm{C}$ lower than the soil covered by $5 \mathrm{~cm}$-thick wood chips.

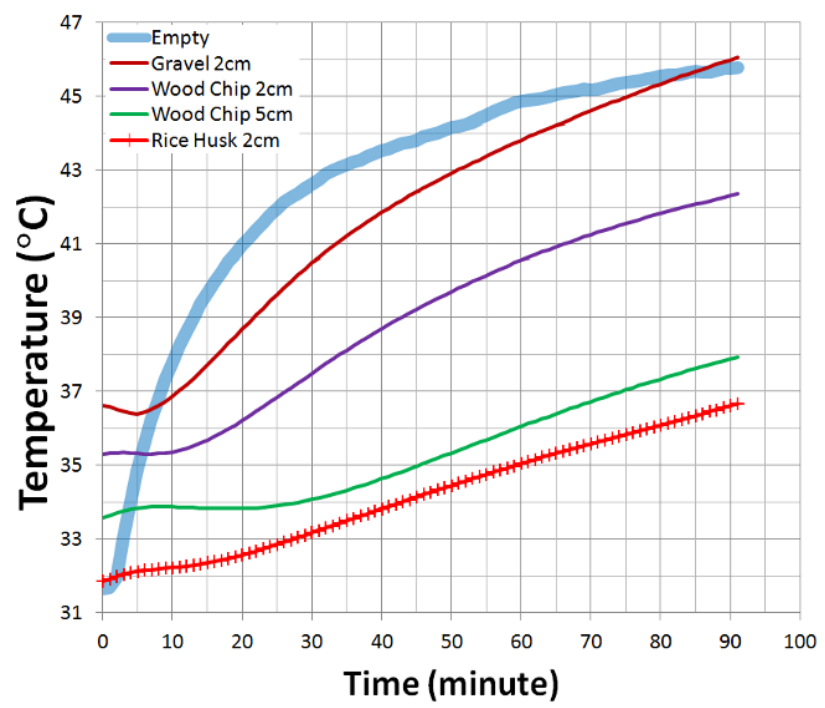

(a) 


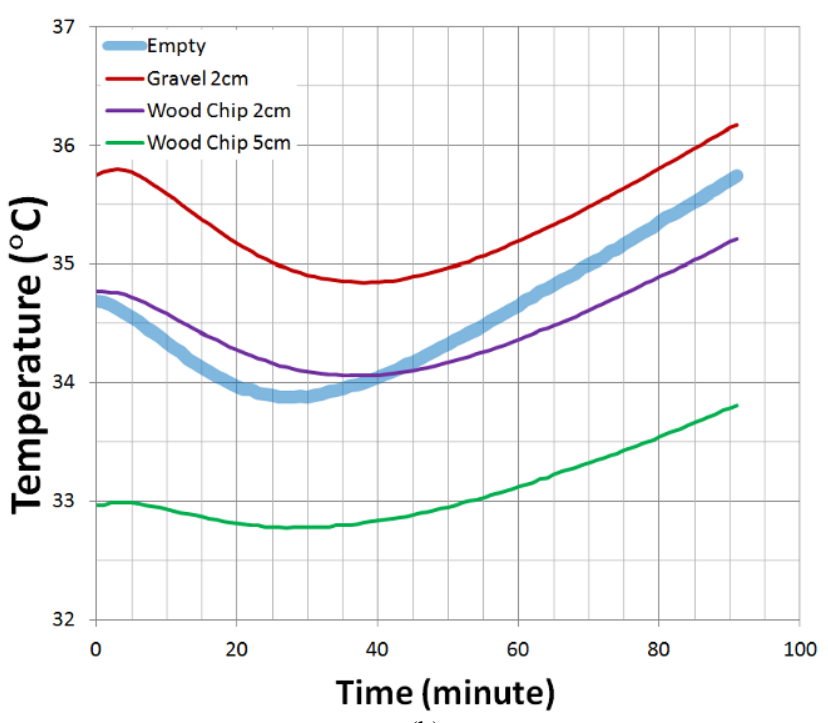

(b)

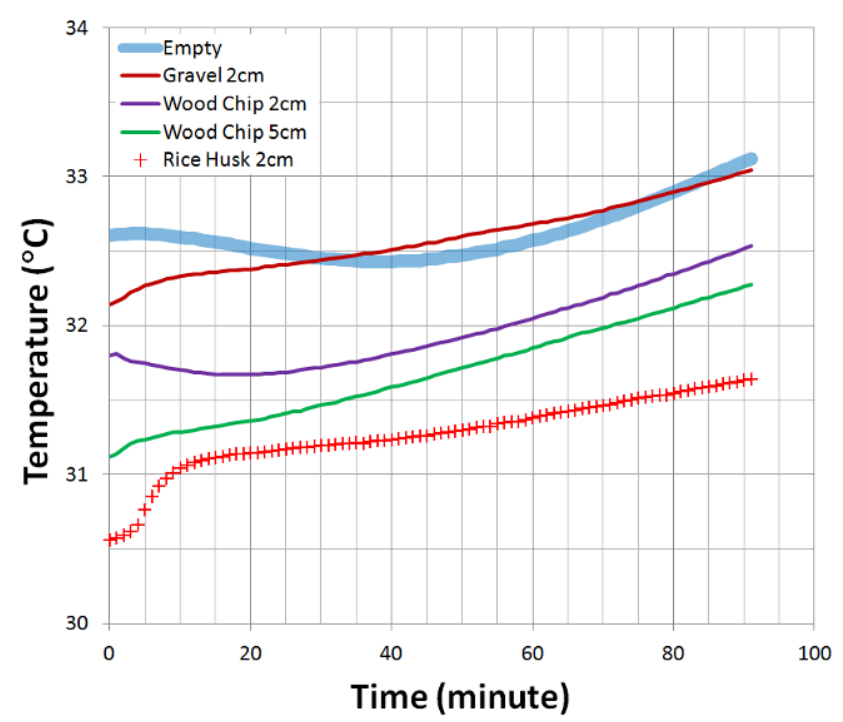

(c)

Fig. 6. Soil temperature (a) at the surface, (b) at the middle of container, and (c) at the bottom of container

TABLE I: THE WEIGHT LOSS OF THE CONTAINER

\begin{tabular}{llll}
\hline \multicolumn{4}{c}{ Average weight (kg) } \\
\hline $\begin{array}{l}\text { Type of } \\
\text { surface }\end{array}$ & $\begin{array}{l}\text { Before } \\
\text { experiment }\end{array}$ & $\begin{array}{l}\text { After } \\
\text { experiment }\end{array}$ & $\begin{array}{l}\text { Weight loss } \\
(\mathrm{kg})\end{array}$ \\
\hline $\begin{array}{l}\text { Empty } \\
\begin{array}{l}\text { Gravel } \\
\text { (2cm-thick) }\end{array}\end{array}$ & 7.74 & 7.62 & 0.12 \\
$\begin{array}{l}\text { Wood Chips } \\
\text { (2cm-thick) }\end{array}$ & 7.24 & 7.16 & 0.04 \\
$\begin{array}{l}\text { Wood Chips } \\
\text { (5cm-thick) }\end{array}$ & 7.49 & 7.18 & 0.06 \\
$\begin{array}{l}\text { Rice Husk } \\
\text { (2cm-thick) }\end{array}$ & 6.81 & 7.40 & 0.09 \\
\hline \hline
\end{tabular}

Table I shows the (moisture) weight loss after the experiment. Soil with open surface experienced the highest weight loss amongst the samples as it is exposed to the direct heating from the halogen light. In spite of the soil surface covered by gravel has the highest temperature, the weight loss of this sample is the least. The gravel layer might have become a shield that holds the moisture within the soil from evaporating. Compared to gravel, wood chips and rice husk are highly porous media that are capable to absorb water like sponge and release through evaporation under the stress of heat. In addition, the $2 \mathrm{~cm}$-thick rice husk has a higher weight loss compared to the $5 \mathrm{~cm}$-thick wood chips shows that the rice husk perform better in the absorption-evaporation process.

\section{CONCLUSION}

Givoni $[10,11]$ found that after the soil was irrigated in the early morning and covered by a $10 \mathrm{~cm}$ thick gravel layer, the temperature of the wet soil at $60 \mathrm{~cm}$ under the ground further reduced $7^{\circ} \mathrm{C}$ compared to the dry bare soil while the maximum ambient temperature above the ground was $34^{\circ} \mathrm{C}$. However, in hot-humid tropical countries like Malaysia, when the soil surface was covered by gravel, the soil temperature was the highest among the samples regardless the depth of soil. This is because Malaysia has humid climate and wet soil throughout the year. The gravel layer might act as a shield that holds the moisture within the soil from evaporating. Furthermore, the gravel has higher thermal conductivity than wood chips and soil. The gravel absorbs the energy from sunlight and transfers it to the soil surface through conduction and radiation. This causes the soil surface to dry. As the soil surface dries, the thermal conductivity of the soil reduces. The dried soil becomes an insulative layer and further moderates the heat transfer from underground to ambient.

In conclusion, wood chips performed better in enhancing the cooling effect of the soil in the outdoor test. This is because they have low thermal conductivity than gravel but higher porosity than gravel. Wood chips could be wetted by wet soil as them have the ability to absorb water and become a heat barrier on the soil surface. The solar radiation falls on the wood chips may cause the absorbed water to evaporate. Through the evaporation process, the heat within soil is extracted, the soil is cooled down. Meanwhile, rice husk produced encouraging results in the indoor test. The soil under the 2-cm-thick rice husk has the lowest temperature. The rice husk that capable to absorb water has a higher surface area than the wood chips. This might enhance its absorption-evaporation process and thus its cooling performance.

\section{REFERENCES}

[1] J. Hansen, R. Ruedy, M. Sato and K. Lo, "Global Temperature in 2011, Trends, and Prospects,” GISS Surface Temperature Analysis, NASA, 2012.

[2] S. A. Chan, "Energy Efficiency: Designing Low Energy Building using Energym,” CPD Seminar, Malaysian Institute of Architects, 2004.

[3] M. A. McNeil and V. E. Letschert, "Future air conditioning energy consumption in developing countries and what can be done about it: the potential of efficiency in the residential sector," Lawrence Berkeley National Laboratory (LBNL) Paper (LBNL-63203), 2008.

[4] M. Isaac and D. P. van Vuuren, "Modeling global residential sector energy demand for heating and air conditioning in the context of climate change,” Energy Policy, vol. 37, pp. 507-521, 2009.

[5] V. A. F. Costa, "Thermodynamic analysis of building heating and cooling using the soil as heat reservoir," Int J Heat and Mass Transfer, vol. 49, pp. 4152-4160, 2006.

[6] Y. Hamada, M. Nakamura, H. Saitoh, H. Kubota, K. Ochifuji, "Improved underground heat exchanger using no-dig method for space heating and cooling,” Renewable Energy, vol. 32, pp. 480-495, 2006. 
[7] A. N. Z. Sanusi, L. Shao, and N. Ibrahim, "Passive ground cooling system for low energy buildings in Malaysia (hot and humid climates)," Renewable Energy, pp. 1-4, 2012.

[8] Y. Hong, Y. Li, and J. Shi, "Geothermal cooling solution research for outdoor cabinet,” IEEE Thermal Investigations of ICs and Systems Conference (THERMINIC) 2009.

[9] Climatetemp Info, "Malaysia Climate Guide to the Average Weather \& Temperatures with Graphs Elucidating Sunshine and Rainfall Data \& Information about Wind Speeds \& Humidity,” Climate \& Temperature Malaysia, Climatetemp Info, 2011.

[10] B. Givoni, "Performance and applicability of passive and low-energy cooling systems,” Energy and Building, vol. 17, pp. 177-199, 1991.

[11] B. Givoni, "Cooled soil as a cooling source for buildings," Solar Energy, vol. 81, pp. 316-328, 2006.

[12] K. H. Lee and R. K. Strand, "The cooling and heating potential of an earth tube system in buildings," Energy and Buildings, vol. 40, pp. 486-494, 2008.

[13] V. Bansal, R. Mishra, G. Das Agarwal and J. Mathur, "Performance analysis of integrated earth-air-tunnel-evaporative cooling system in hot and dry climate,” Energy and Buildings, vol. 47, pp. 525-532, 2012.

[14] S. Wanphen and K. Nagano, "Experimental study of performance of porous materials to moderate the roof surface temperature by its evaporative cooling effect,” Building and Environment, vol. 44, pp. 338-351, 2009.

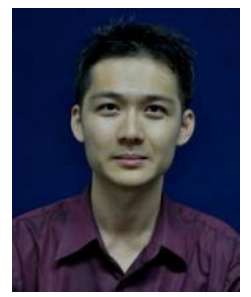

K. W. Chan received his BEng (Hons) in Mechanical Engineering from Universiti Sains Malaysia (USM), Malaysia in 2006. He did his graduate studies in Engineering Science at University of Oxford, United Kingdom, where he received his DPhil in 2011.

He is currently a lecturer at the School of Mechanical Engineering, Universiti Sains Malaysia, Malaysia. His interest is in refrigeration \& air conditioning, renewable energy, and sustainable design.

Dr Keng Wai Chan is a member of IEEE and a senior member of APCBEES. His previous research project was reported in Guardians UK (2008), ranked $31^{\text {st }}$ out of 50 'Time's Best Invention of 2008' by Time Magazine and featured on BBC 'Wallace \& Gromit - World of Invention' (2010). 